\title{
External radiation exposure, excretion, and effective half-life in ${ }^{177}$ Lu-PSMA-targeted therapies
}

\author{
J. Kurth ${ }^{1 *}$ (D, B. J. Krause', S. M. Schwarzenböck', L. Stegger², M. Schäfers² and K. Rahbar²
}

\begin{abstract}
Background: Prostate-specific membrane antigen (PSMA)-targeted therapy with ${ }^{177}$ Lu-PSMA-617 is a therapeutic option for patients with metastatic castration-resistant prostate cancer (mCRPC). To optimize the therapy procedure, it is necessary to determine relevant parameters to define radiation protection and safety necessities. Therefore, this study aimed at estimating the ambient radiation exposure received by the patient. Moreover, the excreted activity was quantified.

Results: In total, 50 patients with mCRPC and treated with ${ }^{177}$ Lu-PSMA-617 (mean administered activity $6.3 \pm 0$. $5 \mathrm{GBq}$ ) were retrospectively included in a bi-centric study. Whole-body dose rates were measured at a distance of $2 \mathrm{~m}$ at various time points after application of ${ }^{177}$ Lu-PSMA-617, and effective half-lives for different time points were calculated and compared. Radiation exposure to the public was approximated using the dose integral. For the estimation of the excreted activity, whole body measurements of 25 patients were performed at 7 time points.

Unbound ${ }^{177}$ Lu-PSMA-617 was rapidly cleared from the body. After $4 \mathrm{~h}$, approximately $50 \%$ and, after $12 \mathrm{~h}$, approximately $70 \%$ of the administered activity were excreted, primarily via urine. The mean dose rates were the following: $3.6 \pm 0.7 \mu \mathrm{Sv} / \mathrm{h}$ at $2 \mathrm{~h}$ p. i., $1.6 \pm 0.6 \mu \mathrm{Sv} / \mathrm{h}$ at $24 \mathrm{~h}, 1.1 \pm 0.5 \mu \mathrm{Sv} / \mathrm{h}$ at $48 \mathrm{~h}$, and $0.7 \pm 0.4 \mu \mathrm{Sv} / \mathrm{h}$ at $72 \mathrm{~h}$. The mean effective half-life of the cohort was $40.5 \pm 9.6 \mathrm{~h}$ ( $\min 21.7 \mathrm{~h}$; $\max 85.7 \mathrm{~h}$ ). The maximum dose to individual members of the public per treatment cycle was $\sim 250 \pm 55 \mu S v$ when the patient was discharged from the clinic after $48 \mathrm{~h}$ and $\sim 190 \pm 36 \mu \mathrm{S} v$ when the patient was discharged after $72 \mathrm{~h}$.

Conclusions: In terms of the radiation exposure to the public, ${ }^{177}$ Lu-PSMA is a safe option of radionuclide therapy. As usually four (sometimes more) cycles of the therapy are performed, it must be conducted in a way that ensures that applicable legal requirements can be followed. In other words, the radiation exposure to the public and the concentration of activity in wastewater must be sub-marginal. Therefore, in certain countries, hospitalization of these patients is mandatory.
\end{abstract}

Keywords: ${ }^{177}$ Lu-PSMA, Dose, Dose rate, Excretion, External radiation exposure, Wastewater

\section{Background}

In recent years, the concept of "theranostics," the effective combination of both imaging and treatment with radiopharmaceuticals using the same molecular target, has been successfully applied to imaging and treatment of castration-resistant prostate cancer (CRPC). CRPC is defined as disease progression despite an androgen-

\footnotetext{
* Correspondence: jens.kurth@med.uni-rostock.de

'Department of Nuclear Medicine, Rostock University Medical Center,

Gertrudenplatz 1, 18057 Rostock, Germany

Full list of author information is available at the end of the article
}

suppression therapy and is the most problematic stage of prostate cancer $(\mathrm{PCa})$. The mean survival time for patients suffering from metastasized CRPC is approximately 1 to 2 years [1].

At present, the prostate-specific membrane antigen (PSMA) is the most widely characterized target antigen in PCa. PSMA is highly and specifically expressed on the surface of $90-100 \%$ of local prostate tumor cells, and in visceral and bone metastases at all tumor stages [2-5], and its expression increases with tumor aggressiveness $[6,7]$. Therefore, PSMA has been proven to be an 
excellent target for prostate cancer imaging and therapy using ${ }^{68} \mathrm{Ga}$ - and ${ }^{177} \mathrm{Lu}$-labeled radiopharmaceuticals, respectively [8].

A high-affinity PSMA ligand (PSMA-617) that shows an excellent tumor-to-background ratio, a rapid blood clearance, and that can be labeled with gallium-68, lutetium-177, or yttrium-90, was introduced by Benesova et al. [9]. Since then, a retrospective German multicenter study [10] also in addition to singlecenter studies, for example from Bad Berka [11], Bonn [12-14], Heidelberg [15, 16], Munich [17, 18] and Muenster [19-21], reported encouraging results for response rates after ${ }^{177} \mathrm{Lu}$-PSMA-targeted therapy. All studies showed that the therapy is well-tolerated. Hematological and renal parameters only changed insignificantly, and permanent xerostomia or other safetyrelated toxicity did not occur. The studies also suggest that the total number of therapy cycles is a positive predictor of the biochemical response. In addition, most importantly, the studies provide indications that ${ }^{177} \mathrm{Lu}$ PSMA-targeted therapy is associated with prolonged patient survival $[20,22,23]$. These promising results will probably lead to a significant increase in the use of PSMA-targeted therapies in the future. A good overview of the countries in Europe in which ${ }^{177}$ Lu-PSMA-targeted therapies are currently conducted is given by the recently published study by Sjögreen Gleisner et al. [24].

However, despite these promising findings, limitations must be critically discussed. As one example, nuclear medicine is always faced with consideration and minimization of the emission of radioactive residues and of the exposure of the population. Therefore, an increased number of therapies also requires a more intensive examination of the activity excreted by the patients and a conservative assessment of the dose which could be absorbed by the public and, in particular, by the relatives and caregivers.

It is known that most of the unbound ${ }^{177}$ Lu-PSMA-617 is excreted via the renal pathway with a high clearance rate $[8,17]$, which may lead to a contamination of public wastewater. In Germany, for instance, the limit for the discharge of lutetium-177 into municipal wastewater is $100 \mathrm{kBq} / \mathrm{ml}$, according to the German Radiation Protection Ordinance [25]. It must also be considered that the incidence of prostate cancer is approximately 40 times higher than the incidence of neuroendocrine tumors (NET) [26-29], which will potentially increase the number of ${ }^{177} \mathrm{Lu}$-based therapies in the near future. The activity in municipal wastewater excreted by all patients could therefore reach a level that exceeds the legally defined limits. For diagnostic radiopharmaceuticals, theoretical values of the proportions of excreted activities can be derived using the information on biokinetic behavior in the body provided by report no. 128 of the International
Commission on Radiological Protection (ICRP) [30]. However, for therapeutically used radiopharmaceuticals, these data can only be determined by direct measurements of the excreted activities.

In the 2007 recommendations of the ICRP and in the European Council Directive 2013/59/Euratom, the dose limit in planned exposure situations for the public is given as $1 \mathrm{mSv}$ per year [31, 32]. A recently published study by Demir et al. aimed at investigating the radiation safety of a treatment protocol for ${ }^{177}$ Lu-PSMA therapy [33]. The researchers concluded that ${ }^{177} \mathrm{Lu}$-PSMA therapy is a safe treatment modality that can be applied as an outpatient protocol and that patients can be released from the radionuclide therapy ward approximately $6 \mathrm{~h}$ after administration of the therapeutic agent. However, a relatively high threshold of the dose rate of $30 \mu \mathrm{Sv} \mathrm{h}^{-1}$ at a distance of $1 \mathrm{~m}$ as release criteria was used, and no additional assessment of the excreted activity in relation to legal limits was performed. In contrast to this procedure in other countries, for instance, in Germany, Austria, or Italy, legal regulations demand hospitalization of these patients. In Germany, patients must be hospitalized for at least $48 \mathrm{~h}$ until the dose rate (measured at a distance of $2 \mathrm{~m}$ ) is below a level warranting the dose to the public to stay below $1 \mathrm{mSv}$ per year. According to the German directive "Radiation Protection in Medicine" [34] and the Recommendations of the German Commission on Radiological Protection [35], the procedure for the release of the patient is clearly defined: at the planned discharge of a patient from the therapy ward, the dose rate must be measured and documented individually. Furthermore, a mono-exponential reduction of the dose rate is assumed; thus, the dose to the public in the patient's environment can be estimated by the time integral of the dose rate. The dose mainly depends on the distance to the patient and on the decrease of the residual activity in the patient, which may be described by the effective half-life.

A study by Fitschen et al. showed that the general framework mentioned above can be applied to peptide receptor radionuclide therapy (PPRT) of NET with ${ }^{177} \mathrm{Lu}$-Dotatoc/Dotatate [36]. If the effective half-life cannot be reasonably estimated from sequential measurements during the stay at the ward, the effective halflife is conservatively estimated to be equal to the physical half-life. However, this may prolong the stay in the hospital unnecessarily. Additionally, it should also be taken into account that in many patients, the therapy with ${ }^{177} \mathrm{Lu}$-PSMA is performed several times per year (normally up to 4 cycles). This will increase the dose to the public and, especially, to relatives and caregivers, as this group of persons is the most exposed category. Therefore, reliable measurements that form the basis to estimate and calculate these doses are necessary. 
Consequently, the aim of this study was to give indications about the renal clearance of ${ }^{177} \mathrm{Lu}$-PSMA-617 through the quantification of the excreted activity with urine and to give an estimate of the radiation exposure to the public caused by patients treated with ${ }^{177} \mathrm{Lu}$ PSMA-617. We also aimed at investigating if it is possible to avoid the estimation of the patient-specific effective half-life during a therapy course by replacing it with a fixed half-life (e.g., the physical or another meaningful upper limit based on the mean effective half-life of a larger patient cohort).

\section{Methods}

Results of measurements from two departments of Nuclear Medicine (Department 1: University of Muenster, Germany; Department 2: University of Rostock, Germany) were aggregated. Data from 50 randomly chosen patients, 25 from each center and treated with 1 cycle of ${ }^{177}$ Lu-PSMA-617, were included in the analysis. Table 1 summarizes the main characteristics of both cohorts.

All patients gave their written consent after being informed about possible side effects and risks of the therapy. Production and quality control of ${ }^{177} \mathrm{Lu}$-PSMA617 were carried out according to the GMP regulations. The detailed labeling procedures were previously described by Ahmadzadehfar et al. [12]. The therapy was conducted in accordance with the German Medicines Law (AMG, $\$ 13[2 \mathrm{~b}]$ ) and the Consensus Recommendations of the German Society of Nuclear Medicine on ${ }^{177} \mathrm{Lu}$ PSMA therapy [18]. According to the German radiation protection regulations [34], all therapies were implemented as inpatient treatment and patients were hospitalized for at least $48 \mathrm{~h}$.

The design of this study was presented to the ethics committee of the Rostock University Medical Center, and the need for a formal review was waived (file no. A 2017-0197). The retrospective and anonymized analysis was carried out in accordance with the Declaration of Helsinki and its later amendments and the legal considerations of clinical guidelines.

Table 1 Main characteristic of the patient cohorts included in the analysis and time points of the dose rate and whole-body activity measurements

\begin{tabular}{lll}
\hline & Department 1 & Department 2 \\
\hline Mean age & $71.4 \pm 9.2$ years & $70.3 \pm 8.3$ years \\
Mean activity & $6.1 \pm 0.5 \mathrm{GBq}$ & $6.6 \pm 0.9 \mathrm{GBq}$ \\
$\begin{array}{l}\text { Time points } t_{i} \text { of the } \\
\text { dose rate measurement }\end{array}$ & 4,24 , and $48 \mathrm{~h} \mathrm{p.} \mathrm{i.}$ & $2,24,48$, and $72 \mathrm{~h} \mathrm{p.i.}$ \\
$\begin{array}{l}\text { Time points } t_{j} \text { of the } \\
\text { whole-body activity } \\
\text { measurement }\end{array}$ & Before the first bladder \\
\hline
\end{tabular}

Lutetium-177 has a physical half-life of approximately 6.7 days and emits $\beta^{-}$particles $\left(E_{\beta}\right.$ of 497,384 , and $176 \mathrm{keV})$ and also $\gamma$ photons with low energy $\left(E_{\gamma}\right.$ of 113 and $208 \mathrm{keV}$ with low emission abundance of 6 and 11\%, respectively) [37]. The therapeutic effect is mainly caused by the $\beta^{-}$component, while the emitted $\gamma$ photons are generally used for the determination of bio-distribution. Therefore, we used external gamma and dose rate probes to carry out the necessary measurements. These types of measurements are robust, easy to perform, and implement into daily clinical routines and additional stress to the patients is minimized.

\section{Measurement of whole-body activity and excreted activity}

The analysis of the excretion of unbound ${ }^{177} \mathrm{Lu}$ PSMA ligands and lutetium-177 was performed indirectly by measuring the remaining activity within the body of the patients at different time points with an external gamma probe. This has been proven to be a fast, simple, and robust method to estimate the activity within the body of the patient [38-41]. The difference compared with the expected activity that can be calculated directly by the physical decay of the administered activity is assumed to be equivalent to the excreted activity.

The measurements were carried out in Department 2, using a cohort of 25 patients (see Table 1). The wholebody activity was measured at $0 \mathrm{~h}$ (before voiding, reference) and approximately at $2,4,12,24,48$, and $72 \mathrm{~h}$ after the administration of ${ }^{177}$ Lu-PSMA- 617.

The remaining activity $A_{\mathrm{WB}}$ in the patient at the given time point $t_{i}$ was determined by the following equation:

$$
A_{\mathrm{WB}}\left(t_{i}\right)=\frac{\sqrt{C_{A}\left(t_{i}\right) \cdot C_{P}\left(t_{i}\right)}}{\mathrm{CF}_{P}},
$$

where $c_{A}\left(t_{i}\right)$ and $c_{P}\left(t_{i}\right)$ are the count rates (compensated for the background) at the given time point for the anterior and posterior views respectively. $\mathrm{CF}_{P}$ is a patient-specific calibration factor based on a baseline measurement of each patient, performed immediately after administration of ${ }^{177} \mathrm{Lu}$-PSMA-617 and before the first voiding of the bladder. This factor is calculated according to the following equation:

$$
\mathrm{CF}_{P}=\frac{\sqrt{C_{A}(0) \cdot C_{p}(0)}}{A_{P}},
$$

where $A_{P}$ is the administered activity. This factor represents the efficiency of the detector for the spatially distributed activity and intrinsically considers the selfattenuation of the $\gamma$ photons by the body of the patient. 
The excreted activity $A_{\mathrm{ex}}$ at the time point $t_{i}$ was calculated as the difference of the whole-body activity at the previous time point $t_{i-1}$ (corrected for decay) and the whole-body activity at the time point $t_{i}$. The whole extracted activity can then be calculated as a summation:

$$
A_{\mathrm{ex}}=\sum_{j=1}^{i}\left(A_{\mathrm{WB}}\left(t_{i-1}\right) e^{-\frac{\ln (2)}{T_{1 / 2}} \cdot\left(t_{i}-t_{i-1}\right)}-A_{\mathrm{WB}}\left(t_{i}\right)\right),
$$

with $T_{1 / 2}$ representing the physical half-life of the radionuclide.

A 3" $\times 3 "$-NaI (Tl) detector (Type 905-4) with multichannel analyzer and software (digiBASE, MAESTRO, Ortec, Oak Ridge, USA) was used as a measurement system. It was calibrated using americium-241, cobalt57, cesium-137, and iodine-131 test sources, and regular quality checks were carried out. The shielded detector (collimator of $3 \mathrm{~cm}$ lead) was positioned $1 \mathrm{~m}$ above the floor, and the field of view covered the whole body of the patient. The energy window was set to $208 \mathrm{keV} \pm 27 \%$, corresponding to approximately $3 \times$ full width at half maximum of the energy resolution of the $\mathrm{NaI}(\mathrm{Tl})$ detector. The background was measured for $300 \mathrm{~s}$ without the presence of a patient. Patients were measured in anterior and posterior standing positions while holding arms close to the body at a distance of $2 \mathrm{~m}$ from the collimator surface. For all measurements, the acquisition time corrected for dead-time effects was set to $90 \mathrm{~s}$. The observed dead-time effect during the calibration measurement for each patient resulted in a loss of detected counts of approximately $5 \%$. No further corrections (e.g., for pile-up or non-linearity) were applied. Statistical uncertainties of the count rate were below $1 \%$ for all measurements, as recommended by Hindorf et al. [41]. Bi-exponential functions were fitted to the data, and the effective half-lives were calculated. The bi-exponential fit model was chosen after comparing the quality of fit of mono- and bi-exponential models using the Akaike criterion as described by Kletting et al. [42]. In addition, the results of dosimetry studies suggest that a bi-exponential fit would be appropriate $[17,43]$.

\section{Measurement of dose rate and estimation of dose to the public}

The measurements and analyses were carried out with 50 patients from both departments as characterized in Table 1. All patients of Department 2 were released from the hospital $72 \mathrm{~h} \mathrm{p}$. i. for organizational reasons. Therefore, dose rate measurements were also available for $t_{i}=$ $72 \mathrm{~h}$ p. i.

The determination of the expected dose $D$ to the public requires knowledge of the dose rate DR at the time point of the release of the patient and of the effective half-life $T_{1 / 2 \text { eff. }}$ The dose $D$ can then be calculated according to the following equation:

$$
D=\frac{\mathrm{DR} \cdot T_{1 / 2_{\mathrm{eff}}}}{\ln 2} .
$$

This equation was originally recommended by the German Commission on Radiological Protection to conservatively estimate the dose to the public after iodine-131 therapy [35]. However, as already mentioned, the study by Fitschen et al. showed that this equation is also applicable in PRRT [36].

In both departments, the dose rate monitor LB 123 DH10 (Berthold Technologies, Bad Wildbad, Germany) was used, which is suitable for dose rate levels between $0.05 \mu \mathrm{Sv} / \mathrm{h}$ and $10 \mathrm{mSv} / \mathrm{h}$ within an energy range from $30 \mathrm{keV}$ to $1.3 \mathrm{MeV}$. The systems were officially calibrated, and regular quality checks were carried out. The patients were measured in the standing position from the anterior $\left(\mathrm{DR}_{A}\right)$ and posterior $\left(\mathrm{DR}_{P}\right)$ view at a distance of $2 \mathrm{~m}$ from the surface of the detector. The dose rate DR for different time points (see Table 1) was then calculated as the geometric mean of both measurements

$$
\mathrm{DR}\left(t_{i}\right)=\sqrt{\mathrm{DR}_{A}\left(t_{i}\right) \cdot \mathrm{DR}_{P}\left(t_{i}\right)} .
$$

The data were fitted by a mono-exponential curve, and the effective half-life was calculated for the different time points: 24,48 , and $72 \mathrm{~h}$ (only from the data of Department 2). Since at least two data points are necessary for the fitting, the effective half-life was calculated from the following measurement points: $24 \mathrm{~h}(2 \mathrm{~h} / 4 \mathrm{~h}$ and $24 \mathrm{~h}), 48 \mathrm{~h}(24 \mathrm{~h}$ and $48 \mathrm{~h})$, and $72 \mathrm{~h}(24 \mathrm{~h}, 48 \mathrm{~h}$ and $72 \mathrm{~h}$ ). For all comparisons, the time point $48 \mathrm{~h}$ was chosen as the reference, because it is standard that the patients are released from the therapy ward after $48 \mathrm{~h}$. Subsequently, Eq. 4 was used to determine the dose $D$ to the public after the discharge of the patient for different time points of release $(24,48$, and $72 \mathrm{~h}$ p. i.), substituting $T_{1 / 2 \text { eff }}$ by $T_{1 / 2 \text { ind }}$ (individual half-life of each patient), $T_{1 / 2 \text { phys }}$ (physical half-life of ${ }^{177} \mathrm{Lu}$ ), and $T_{1 / 2 \max }$ (maximum of the calculated effective half-life of the patient cohort) for different calculations. In addition, a correlation analysis (Spearman and Pearson) of the dose rate and administered activity was performed.

\section{Data processing and statistical analysis}

Data processing and fitting were performed using inhouse coded and validated LabVIEW applications (ver. 2016, Nat. Instruments), and SPSS (ver. 22.0, IBM Corp.) was used for the statistical analysis. Statistical differences were assessed using non-parametric tests for unpaired and paired samples (Mann-Whitney $U$ test and 
Wilcoxon signed-rank test). A value of $p \leq 0.05$ was assumed to indicate statistical significance. Data are presented as the mean and standard deviation unless stated otherwise.

\section{Results}

\section{Whole-body measurement and analysis of excreted} activity

The measured time-activity curves (Fig. 1) revealed rapid clearance of the therapeutic agent from the body within the first few hours after infusion and a second slower phase. The calculated effective half-lives for the first and the second phase were $1.7 \pm 0.8 \mathrm{~h}$ and $41.1 \pm 9.3 \mathrm{~h}$, respectively. No correlation was found between administered activity and measured half-lives (Pearson's $r=0.08$, Spearman's rho $=0.07$ ).

Table 2 summarizes the excreted activity of ${ }^{177} \mathrm{Lu}$ PSMA-617 for the different time points of measurement (calculated using Eq. 3) and the percentage of overall excreted activity. After approximately $4 \mathrm{~h}$, approximately $50 \%$ and, after $12 \mathrm{~h}$, almost $70 \%$ of the administered activities were excreted. Thereafter, the renal elimination decreased markedly. On average, approximately $4.8 \mathrm{GBq}$ of the administered $6.6 \mathrm{GBq}{ }^{177} \mathrm{Lu}$-PSMA-617 were excreted over a period of $72 \mathrm{~h}$.

\section{Measurement of dose rate and estimation of half-life and dose}

The measured dose rates at the different time points are summarized in Table 3, and Fig. 2a shows the course of the dose rate. Clearly, the drop of the dose rate is highest during the first $24 \mathrm{~h}$, due to the fast excretion of the compound that can also be seen in the results of the first

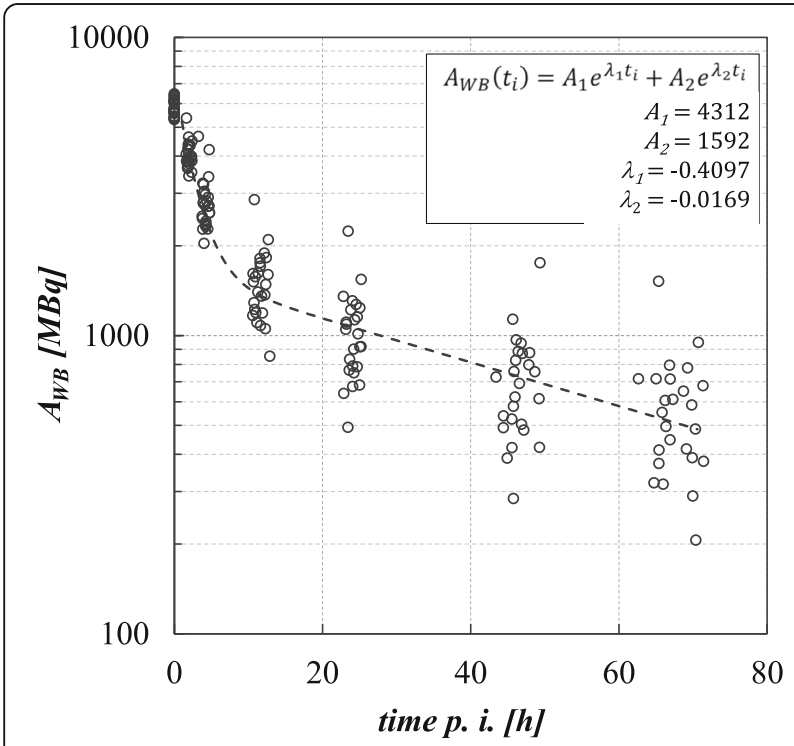

Fig. 1 Time-activity curve of the measured whole-body activity and mean bi-exponential fit to the data part of this study (see Fig. 1). Only a weak or no correlation between the measured dose rate and administered activity was found (Pearson's $r=0.17$; Spearman's rho $=$ $0.18)$.

Statistical tests of the calculated half-lives revealed no significant differences between the data of both cohorts (Mann-Whitney $U$ test, $p=0.841$ for $24 \mathrm{~h}$ and $p=0.883$ for $48 \mathrm{~h}$ ). Therefore, the datasets of both departments were aggregated for further analysis.

The results for the calculated effective half-life at the different time points are summarized in Table 3. The histogram of the classified individual effective half-lives (calculated $48 \mathrm{~h} \mathrm{p}$. i.) for a class size of $5 \mathrm{~h}$ is shown in Fig. 2b. For most of the patients, a half-life between 35 and $40 \mathrm{~h}$ was calculated. In general, the results showed considerable variance (e.g., for the 48-h measurement point between 21.7 and $85.7 \mathrm{~h}$, mean $40.5 \pm 15.8 \mathrm{~h}$ ) (illustrated in Fig. 3), and there were clear differences between the half-lives at the different measurement points. The calculated half-life after $24 \mathrm{~h}$ was significantly lower than after $48 \mathrm{~h}$ (Wilcoxon signed-rank test for paired samples, $p=0.016$ ), caused by the influence of the initial rapid clearance of the compound (see the "Results" section in the paragraph above). Therefore, it seems inappropriate to use early time points of measurement to calculate the effective half-life and the dose to the public, as the calculated dose would be underestimated. No significant differences were found for the effective half-life after 48 and $72 \mathrm{~h}$ (Wilcoxon signed-rank test for paired samples $p=0.851)$. Therefore, in the sense of a conservative approach, we used the half-life of the slower elimination phase (calculated after $48 \mathrm{~h}$ ) for further calculations of the dose $D$, as this is the main influence to the dose to the public.

The results for the calculated doses to the public after discharge of the patient using the three different types for the effective half-life are summarized in Table 4, which also adds a more detailed view of the minimum and maximum values.

The expected dose to the public is below $1 \mathrm{mSv}$ per cycle of therapy. When discharging the patient $48 \mathrm{~h} \mathrm{p}$. i., the expected dose is on average approximately $70 \mu \mathrm{Sv}$ with a maximum of approximately $260 \mu \mathrm{Sv}$ when the individual effective half-life is used for the calculation. Even in the case of an earlier release at $24 \mathrm{~h}$ p. i., the assumed dose to the public is on average $100 \mu \mathrm{Sv}$ with a of approximately $320 \mu \mathrm{Sv}$ per cycle.

If the physical half-life of lutetium-177 is used for the calculation (conservative approach), the estimated dose is still well below $1 \mathrm{mSv}$ per cycle. However, the average dose to the public will be overestimated by approximately $350 \%$, in some cases by up to $640 \%$, as the individual half-life is much lower than the physical half-life of lutetium-177. The use of the maximum half-life of 
Table 2 Excreted activity $\left(A_{\text {ex }}\left(t_{i}\right)\right)$ between a given time point and the previous time point and the percentage comparison of the overall amount of excreted activity and administered activity

\begin{tabular}{|c|c|c|c|c|c|c|c|c|c|c|c|c|}
\hline \multirow[t]{3}{*}{ Time p. i. } & \multicolumn{2}{|l|}{$2 \mathrm{~h}$} & \multicolumn{2}{|l|}{$4 \mathrm{~h}$} & \multicolumn{2}{|l|}{$12 \mathrm{~h}$} & \multicolumn{2}{|l|}{$24 \mathrm{~h}$} & \multicolumn{2}{|l|}{$48 \mathrm{~h}$} & \multicolumn{2}{|l|}{$72 \mathrm{~h}$} \\
\hline & \multicolumn{2}{|l|}{$A_{\text {ex }}$} & \multicolumn{2}{|l|}{$A_{\text {ex }}$} & \multicolumn{2}{|l|}{$A_{\text {ex }}$} & \multicolumn{2}{|l|}{$A_{\mathrm{ex}}$} & \multicolumn{2}{|l|}{$A_{\text {ex }}$} & \multicolumn{2}{|l|}{$\underline{A_{\text {ex }}}$} \\
\hline & {$[\mathrm{MBq}]$} & [\%] & {$[\mathrm{MBq}]$} & {$[\%]$} & {$[\mathrm{MBq}]$} & {$[\%]$} & {$[\mathrm{MBq}]$} & {$[\%]$} & {$[\mathrm{MBq}]$} & {$[\%]$} & {$[\mathrm{MBq}]$} & [\%] \\
\hline Mean & 1718 & 30 & 1265 & 50 & 1155 & 70 & 395 & 76 & 219 & 77 & 68 & 78 \\
\hline Std. Dev. & 500 & 8 & 126 & 8 & 72 & 7 & 38 & 7 & 26 & 8 & 7 & 7 \\
\hline Min & 735 & 13 & 1060 & 30 & 1009 & 48 & 318 & 53 & 160 & 50 & 50 & 54 \\
\hline Max & 2621 & 42 & 1526 & 62 & 1323 & 82 & 474 & 87 & 265 & 89 & 82 & 89 \\
\hline
\end{tabular}

our cohort $T_{1 / 2 \max }$ of $85 \mathrm{~h}$ results in a conservative dose estimate that is reduced by approximately $90 \%$ compared to the use of the physical half-life.

\section{Discussion}

In the relatively short time since entering the clinical arena, PSMA-targeted therapies have shown promising results and a further intensification of their use is to be expected. Due to the increasing number of radionuclide therapies, radiation protection issues must also be taken into account when optimizing therapy protocols. In the work presented here, we describe the results of some essential aspects of radiation protection in the context of ${ }^{177}$ Lu-PSMA therapy, namely, the exposure of the general population by treated patients and the excretion of unbound or metabolized radioactive PSMA compounds.

Unbound ${ }^{177}$ Lu-PSMA-617 is mainly excreted through the renal pathway with a fast renal clearance, due to the low molecular weight of the compound [9]. As known from PRRT of NET, the amount of activity in the excreted feces and perspiration is also negligible for PSMA ligands $[8,9]$. Our results show the two phases of excretion; a faster initial clearance with a half-life of approximately $2 \mathrm{~h}$ and a much slower clearance of approximately $41 \mathrm{~h}$, also qualitatively described by Kulkarni et al. and Hohberg et al. [11, 44] and known from the PRRT of NET $[45,46]$. The clearance of ${ }^{177} \mathrm{Lu}-$ PSMA-617 is faster than the clearance known from ${ }^{177} \mathrm{Lu}$-Dotatoc/Dotatate (effective half-life approximately $56 \mathrm{~h})[36,45]$. Our results show that within the first $12 \mathrm{~h}$ after the administration of ${ }^{177}$ Lu-PSMA-617, the majority of the administered activity is excreted (approximately $70 \pm 7 \%$ ). These results are comparable to those known from PPRT of NET with ${ }^{177} \mathrm{Lu}$-Dotatoc/ Dotatate, as studies by Esser et al. and Calais et al. have shown that after $6 \mathrm{~h}$, nearly 45 to $50 \%$ and, after $12 \mathrm{~h}$, approx. 65 to $70 \%$ of Dotatoc/Dotatate compounds are excreted by urine [46, 47]. Furthermore, a recently published study by Demir et al. also analyzed the excreted activity in a group of 7 patients treated with ${ }^{177}$ Lu-PSMA-617 [33]. The researchers observed that a mean of $45 \%$ (range, 32-65\%) of the administered activity is excreted within the first $6 \mathrm{~h}$, which is somewhat lower but comparable to our results. However, no results for the following days and the overall amount of excreted activity are reported.

To determine the renal excreted activity, the activity in the urine is usually measured. By contrast, we opted for the indirect determination of excreted activity, because the measurements of the specific activity in the collected urine showed several disadvantages in clinical routine. Some of the disadvantages include incomplete urine collection, contamination, and an increased patient

Table 3 Measured dose rates and calculated effective half-lives at different time points

\begin{tabular}{|c|c|c|c|c|c|}
\hline Time point & $2 \pm 0.3 \mathrm{~h}$ & $3.9 \pm 0.7 \mathrm{~h}$ & $24.2 \pm 0.7 \mathrm{~h}$ & $45.7 \pm 2.1 \mathrm{~h}$ & $67.7 \pm 2.3 h^{a}$ \\
\hline \multicolumn{6}{|c|}{ Dose rate $[\mu \mathrm{S} v / \mathrm{h}]$ (measured at a distance of $2 \mathrm{~m}$ ) } \\
\hline Mean & 3.6 & 2.8 & 1.6 & 1.1 & $0.7^{\mathrm{a}}$ \\
\hline Std. Dev. & 0.7 & 0.6 & 0.6 & 0.5 & $0.4^{\mathrm{a}}$ \\
\hline Min & 2.2 & 1.3 & 0.5 & 0.4 & $0.1^{\mathrm{a}}$ \\
\hline Max & 5.0 & 3.8 & 1.4 & 2.3 & $2.1^{\mathrm{a}}$ \\
\hline \multicolumn{6}{|c|}{ Calculated effective half-life $T_{1 / 2 \text { eff }}$} \\
\hline Mean & - & - & 26.0 & 40.5 & $38.4^{\mathrm{a}}$ \\
\hline Std. Dev. & - & - & 12.4 & 15.8 & $9.6^{\mathrm{a}}$ \\
\hline Min & - & - & 11.0 & 21.7 & $25.7^{\mathrm{a}}$ \\
\hline Max & - & - & 73.5 & 85.7 & $74.5^{a}$ \\
\hline
\end{tabular}

${ }^{\mathrm{a} T h e s e ~ d a t a ~ a r e ~ o n l y ~ a v a i l a b l e ~ f o r ~} 25$ patients (cohort of Department 2) 

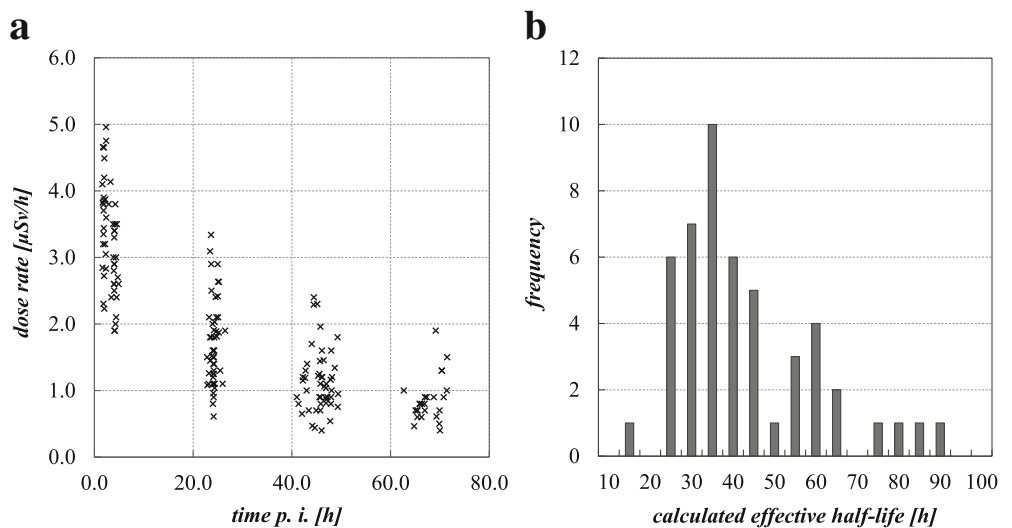

Fig. 2 a Measured dose rates DR for all patients $(n=50)$. b Frequency distribution of the measured effective half-lives after $48 \mathrm{~h}$

stress, owing to the fact that many patients suffering from $\mathrm{mCRPC}$ also suffer from a strong urge to urinate, frequent urination, or incontinence. Therefore, we determined the excreted activity on the basis of measurements of whole-body activity at different time points using an external gamma probe. A potential source of uncertainty discussed in the context of activity

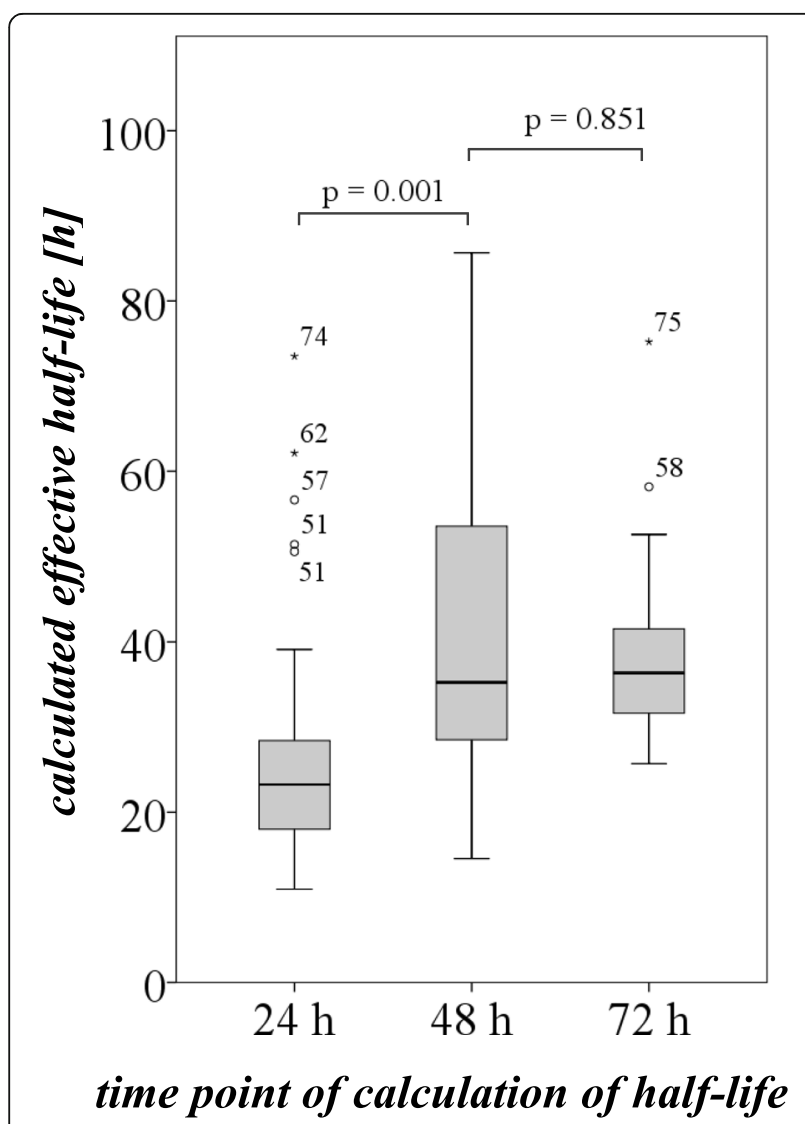

Fig. 3 Calculated half-lives at different time points. The half-life at $24 \mathrm{~h}$ (calculated from the time points 2 or 4 and $24 \mathrm{~h}$ ) is significantly underestimated, due to the influence of the first washout phase determination by whole-body measurements is the varying activity in the bladder during the baseline measurement and differences of the activity redistribution in the patient body during subsequent measurements. A recently published study by Liu et al. compared the results of the urine collection method and whole-body measurements in patients treated with ${ }^{177} \mathrm{Lu}$-Dotatate [48]. They found that the excreted activities determined by whole-body measurements were overestimated by approximately $14 \%$ at $1 \mathrm{~h} \mathrm{p}$. i. and randomly varied from 29 to $49 \%$ at $24 \mathrm{~h}$. The authors also proposed a modified setup of the whole-body measurements: a series of paired measurements before and after each voiding of the bladder to correct for the effects of the varying activity distribution. However, it was not possible in our cohort of patients to establish this comparatively extensive measuring regimen, since many patients felt a strong sudden urge to urinate. Due to that, the individual reference measurements, which are necessary before each use of the toilet, often could not be acquired by the technicians, and thus, the necessary correction factors could not be calculated. On the other hand, a study on dosimetry for ${ }^{177} \mathrm{Lu}$-PSMA-617 therapies by Hohberg et al. [44] showed only minor deviations between wholebody activities measured by external gamma probes and the activities measured by planar whole body gamma camera imaging; planar whole body scintigraphy is assumed to be the most accurate method in this case. The whole body doses calculated from the resulting timeactivity curves also showed only minor differences $(\leq 2$. $36 \pm 1.69 \%$ ). Based on this result, we decided to use the conservative and well-known approach of measuring whole-body activity using external gamma probes.

On average, $4.81 \mathrm{GBq}$ and maximally up to $6.29 \mathrm{GBq}$ of lutetium-177 are excreted per therapy cycle and patient (see Table 2) based on an average therapeutic activity of $6.6 \mathrm{GBq}$ in patient cohort 2. Due to the high incidence of prostate cancer, this will certainly lead to an 
Table 4 Calculated doses to the public for each cycle of ${ }^{177}$ Lu-PSMA-617 therapy for different time points of discharge of the patient from the hospital using different assumptions for the effective half-life

\begin{tabular}{|c|c|c|c|c|c|c|c|c|c|}
\hline \multicolumn{10}{|c|}{ 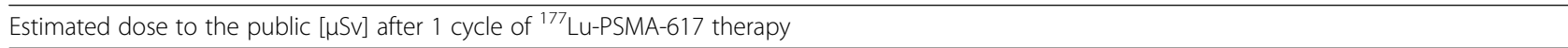 } \\
\hline \multirow{2}{*}{$\begin{array}{l}\text { Time point of discharge } \\
\text { Type of half-life }\end{array}$} & \multicolumn{3}{|c|}{24 h p. i. ${ }^{\text {a }}$} & \multicolumn{3}{|c|}{48 h p.i. } & \multicolumn{3}{|c|}{72 h p. i. ${ }^{b}$} \\
\hline & $T_{1 / 2 \text { ind }}$ & $T_{1 / 2 \text { phys }}$ & $\overline{T_{1 / 2 \max }}$ & $T_{1 / 2 \text { ind }}$ & $T_{1 / 2 \text { phys }}$ & $\overline{T_{1 / 2 \max }}$ & $T_{1 / 2 \text { ind }}$ & $T_{1 / 2 \text { phys }}$ & $T_{1 / 2 \max }$ \\
\hline Mean & 99 & 396 & 208 & 71 & 263 & 139 & 50 & 200 & 105 \\
\hline Std. Dev. & 58 & 131 & 69 & 51 & 100 & 53 & 35 & 76 & 40 \\
\hline Min & 25 & 142 & 75 & 13 & 93 & 49 & 17 & 93 & 49 \\
\hline Max & 318 & 779 & 410 & 264 & 560 & 294 & 204 & 443 & 233 \\
\hline
\end{tabular}

${ }^{a}$ For the effective individual half-life, the value from the 48-h measurement point was used (see the "Results" section)

${ }^{\mathrm{b}}$ These data are only available for 25 patients (cohort of Department 2)

increased concentration of lutetium-177 in wastewater. Particular attention must be paid in compliance with legal and local regulations and statutory thresholds where applicable. It should also be noted that the incidence of prostate carcinoma, and thus the number of expected therapies, is considerably higher than the incidences we know from NET therapies. Furthermore, experience from the NET therapies with ${ }^{177} \mathrm{Lu}$-Dotatoc/ Dotatate have shown that, differing from the standard therapy regimen (e.g., the NETTER 1 trial, $4 \times 7.4 \mathrm{GBq}$ ) [49], also, more than 4 cycles per patient are tolerated very well. This was demonstrated by a recently published study by Yordanova et al. [50], for example, in which up to 13 cycles of PRRT with a median activity of 63.8 GBq were administered without severe toxicity. This finding is also to be expected for PSMA-targeted therapies; therefore, the amount of wastewater contaminated with lutetium-177 will most likely increase. When balancing the quantities of liquid waste of a nuclear medicine ward, the excreted activities of other therapies also have to be considered. If, for instance, both PSMA and Dotatoc/Dotatate therapies are performed, an excretion factor of $90 \%$ can be used independently for both therapies to assess the excreted activity. This conservative value takes into account both the results of studies on excretion in Dotatoc/Dotatate therapies [46, 47] and the results published by Demir et al. [33] and our results on PSMA therapies.

The results for dose rate measurement and estimation of dose to the general public are not as critical. Our test results are based on measurements at a distance of $2 \mathrm{~m}$ according to legal requirements in Germany. The fast component of the kinetics, with a half-life of $1.7 \mathrm{~h}$, does not provide any relevant contribution to the dose of the general public. The mean value determined for the effective half-life is approximately $41 \mathrm{~h}$ in ${ }^{177}$ Lu-PSMA617-targeted therapies. The calculated doses to the public show great variations. However, it can be clearly seen from Tables 1 and 4 that, if the individually calculated half-life can be used for dose estimation, for the majority of the patients, the dose limit for the general public of $1 \mathrm{mSv} /$ year will not be reached even in the case of several therapy cycles per year, and also, no adjustments of the hospital stay are necessary. However, the dose limits are exceeded in some patients, especially in patients with a high tumor load or impaired kidney function and in cases of early discharge and more than two therapy cycles per year. If it is not possible to perform the necessary measurements to calculate the individual half-life, for instance, due to the poor health status of the patient, the use of the maximum effective half-life of $85.7 \mathrm{~h}$ for the dose estimation is a good alternative as already proposed by Fitschen et al. for ${ }^{177} \mathrm{Lu}$ Dotataoc/Dotatate therapies [36]. If the physical half-life of lutetium-177 is used instead, the dose to the public will be overestimated by several hundred percent (see Table 4). However, this approach is too conservative and may lead to an unnecessary prolongation of the hospital stay. However, if more cycles of PSMA-targeted therapy per year and patient are conducted, the estimated dose to the public for each cycle should be summed to an individual annual dose. If this result shows that the limit of $1 \mathrm{mSv}$ might be exceeded, the patient's stay in the hospital can be adjusted accordingly.

The safety of ${ }^{177} \mathrm{Lu}$ PSMA administration to staff and caregivers was also emphasized in the previously cited study by Demir et al. [33]. The authors measured radiation doses delivered both to administering staff and family in 23 patients and found that the mean dose rate at $1 \mathrm{~m}$ after 4 and $6 \mathrm{~h}$ was $23 \pm 6 \mu \mathrm{Sv} / \mathrm{h}$ and $15 \pm 4 \mu \mathrm{Sv} / \mathrm{h}$, respectively. They also found that the mean dose received by close family members was $202 \pm 43 \mu \mathrm{Sv}$, measured for 5 days post-injection with an optically stimulated luminescence dosimeter. These doses are slightly higher than those calculated in our study; however, the administered activity was higher (7.5 GBq compared to $6.3 \mathrm{GBq}$ ), and all of the patients were released from the hospital $6 \mathrm{~h} \mathrm{p}$. i. Both factors increase the dose rate, and therefore, the dose received by the close family members would be higher. In summary, the results show that the equation used in our study (Eq. 4) provides a good estimation of the dose to relatives and caregivers. 
When interpreting the results of our study with regard to dose limits, any differences between the general population and relatives that may have been made by legal regulations must be taken into account. For instance, in the German Radiation Protection Ordinance and in the European Council Directive 2013/59/Euratom, no difference is made between the group of relatives and caregivers and the general public; for both groups, the dose limit is $1 \mathrm{mSv}$ per year [25, 32]. The ICRP recommends a dose limit of $1 \mathrm{mSv}$ per year for the general public and up to $5 \mathrm{mSv}$ per year for relatives and caregivers [31]. It must also be noted that the results of our study are based on patients treated with ${ }^{177} \mathrm{Lu}$-PSMA-617. However, comparable results can be expected also for other PSMA ligands, such as PSMA-I\&T because these ligands do not significantly differ in biokinetics [11].

In general, the success of therapies with Dotatoc/Dotatate and PSMA ligands will potentially lead to an increase of radionuclide therapies with lutetium-177 in clinical routine, because at present, these therapies have also shown promising results with respect to response rates with only minor side effects $[21,49,51]$. Promising new targets for the concept of theranostics are on the horizon, such as the chemokine receptor 4 (CXCR4) [52], the gastrin releasing peptide receptor [53, 54], and integrin $\alpha_{v} \beta_{3}$ [55]. Therefore, it is certainly not an exaggeration to state that we will see an increased use of ${ }^{177} \mathrm{Lu}$-labeled therapeutics in the near future. This aspect also has to be taken into account when therapy protocols and the necessary radiation protection measures (inpatient or outpatient treatment, time point of discharge, etc.) are planned. In this context, the treatment of wastewater from nuclear medicine therapy wards and their compliance with the legal regulations must also be considered. For instance, a series of simple screening techniques that can be used to demonstrate compliance with administratively set reference levels for the release of radionuclides is provided by report no. 123 of the National Council on Radiation Protection and Measurements (NCRP) [56]. If there are doubts about compliance with legal limits, the hospitalization of the patients at a therapy ward with an appropriate decay tank is an option if this is not already prescribed by law, as it is in Germany.

\section{Conclusions}

Due to the expected increase in PSMA-targeting therapies, radiation protection with regard to the exposure of the general public and the excretion of free or metabolized activity must be considered. In case of the appropriate adaptation of the discharge time point, it is possible to comply with the recommended dose limit of $1 \mathrm{mSv}$ per year for the general public according to ICRP 103 , even in the case of performing several therapy cycles per calendar year and patient. If the effective halflife cannot be determined individually, a maximum value of approximately $85 \mathrm{~h}$ can be used instead of the physical half-life of lutetium-177 to conservatively calculate the expected dose to the general public. However, special attention must be paid to the activity excreted with the urine. Depending on local conditions (e.g., the number of treated patients, amount of wastewater), the activity concentration in the wastewater will potentially have to be taken into account, especially in light of the rising numbers of ${ }^{177} \mathrm{Lu}$-based therapies.

\section{Abbreviations}

ICRP: International Commission on Radiological Protection; mCRPC: Metastasized castration-resistant prostate cancer; NCRP: National Council on Radiation Protection and Measurements; NET: Neuroendocrine tumor; PRRT: Peptide receptor radionuclide therapy; PSMA: Prostate-specific membrane antigen

\section{Acknowledgements}

The authors are grateful to the radiopharmacy groups of both departments for the production of ${ }^{177} \mathrm{Lu}-\mathrm{PSMA}-617$ and the excellent technical support by the technicians. The manuscript was edited by American Journal Experts (AJE).

Availability of data and materials

The datasets generated and analyzed during the current study are available from the corresponding author on a reasonable request.

\section{Authors' contributions \\ JK and KR designed the study, performed the data analysis, and wrote the manuscript. BK and MS contributed to the analysis and interpretation of the data. SS and LS contributed to the preparation of the study and the interpretation of the data. All authors read and approved the final version of the manuscript.}

\section{Ethics approval and consent to participate}

All procedures performed were in accordance with the ethical standards of the institutional and/or national research committee and with the 1964 Helsinki declaration and its later amendments or comparable ethical standards. The need for a formal review of this retrospective study was waived by the Ethical Committee of the University of Rostock (file no. A 2017-0197). All patients gave their written consent after being informed about possible side effects and risks of the therapy.

\section{Competing interests}

The authors declare that they have no competing interests.

\section{Publisher's Note}

Springer Nature remains neutral with regard to jurisdictional claims in published maps and institutional affiliations.

\section{Author details}

'Department of Nuclear Medicine, Rostock University Medical Center, Gertrudenplatz 1, 18057 Rostock, Germany. ${ }^{2}$ Department of Nuclear Medicine, University Hospital Muenster, Muenster, Germany.

Received: 28 November 2017 Accepted: 2 April 2018

Published online: 12 April 2018

\section{References}

1. Kirby M, Hirst C, Crawford ED. Characterising the castration-resistant prostate cancer population: a systematic review. Int J Clin Pract. 2011;65(11):1180-92.

2. Wright GL Jr, Haley C, Beckett ML, Schellhammer PF. Expression of prostatespecific membrane antigen in normal, benign, and malignant prostate tissues. Urol Oncol. 1995:1 (1):18-28.

3. Rybalov M, Ananias HJ, Hoving HD, van der Poel HG, Rosati S, de Jong IJ. PSMA, EpCAM, VEGF and GRPR as imaging targets in locally recurrent prostate cancer after radiotherapy. Int J Mol Sci. 2014;15(4):6046-61. 
4. Minner S, Wittmer C, Graefen M, Salomon G, Steuber T, Haese A, et al. High level PSMA expression is associated with early PSA recurrence in surgically treated prostate cancer. Prostate. 2011;71(3):281-8.

5. Lutje S, Heskamp S, Cornelissen AS, Poeppel TD, van den Broek SA, Rosenbaum-Krumme $\mathrm{S}$, et al. PSMA ligands for radionuclide imaging and therapy of prostate cancer: clinical status. Theranostics. 2015;5(12):1388-401.

6. Israeli RS, Powell CT, Corr JG, Fair WR, Heston WD. Expression of the prostate-specific membrane antigen. Cancer Res. 1994;54(7):1807-11.

7. Carter RE, Feldman AR, Coyle JT. Prostate-specific membrane antigen is a hydrolase with substrate and pharmacologic characteristics of a neuropeptidase. Proc Natl Acad Sci U S A. 1996;93(2):749-53.

8. Eder M, Schafer M, Bauder-Wust U, Hull WE, Wangler C, Mier W, et al. 68Gacomplex lipophilicity and the targeting property of a urea-based PSMA inhibitor for PET imaging. Bioconjug Chem. 2012;23(4):688-97.

9. Benesova M, Schafer M, Bauder-Wust U, Afshar-Oromieh A, Kratochwil C, Mier W, et al. Preclinical evaluation of a tailor-made DOTA-conjugated PSMA inhibitor with optimized linker moiety for imaging and endoradiotherapy of prostate cancer. J Nucl Med. 2015;56(6):914-20.

10. Rahbar K, Ahmadzadehfar H, Kratochwil C, Haberkorn U, Schafers M, Essler $M$, et al. German multicenter study investigating 177Lu-PSMA-617 radioligand therapy in advanced prostate cancer patients. J Nucl Med. 2017;58(1):85-90.

11. Kulkarni HR, Singh A, Schuchardt C, Niepsch K, Sayeg M, Leshch Y, et al. PSMA-based radioligand therapy for metastatic castration-resistant prostate cancer: the Bad Berka experience since 2013. J Nucl Med. 2016;57(Suppl 3): 97S-104S.

12. Ahmadzadehfar H, Rahbar K, Kurpig S, Bogemann M, Claesener M, Eppard E, et al. Early side effects and first results of radioligand therapy with (177) LuDKFZ-617 PSMA of castrate-resistant metastatic prostate cancer: a twocentre study. EJNMMI Res. 2015;5(1):114.

13. Ahmadzadehfar H, Eppard E, Kurpig S, Fimmers R, Yordanova A, Schlenkhoff $C D$, et al. Therapeutic response and side effects of repeated radioligand therapy with 177Lu-PSMA-DKFZ-617 of castrate-resistant metastatic prostate cancer. Oncotarget. 2016;7(11):12477-88.

14. Schlenkhoff CD, Knupfer E, Essler M, Ahmadzadehfar H. Metastatic prostate cancer with restored hormone-response after radioligand therapy with 177Lu-PSMA-617. Clin Nucl Med. 2016;41(7):572-3.

15. Kratochwil C, Giesel FL, Eder M, Afshar-Oromieh A, Benesova M, Mier W, et al. [(177) Lu] lutetium-labelled PSMA ligand-induced remission in a patient with metastatic prostate cancer. Eur J Nucl Med Mol Imaging. 2015;42(6):987-8

16. Rathke H, Giesel FL, Flechsig P, Kopka K, Mier W, Hohenfellner M, et al. Repeated Lu-177-PSMA-617 radioligand therapy using treatment activities up to $9.3 \mathrm{GBq}$. J Nucl Med. 2017;59(3):459-465.

17. Delker A, Fendler WP, Kratochwil C, Brunegraf A, Gosewisch A, Gildehaus FJ, et al. Dosimetry for (177) Lu-DKFZ-PSMA-617: a new radiopharmaceutical for the treatment of metastatic prostate cancer. Eur J Nucl Med Mol Imaging. 2016;43(1):42-51

18. Fendler WP, Kratochwil C, Ahmadzadehfar H, Rahbar K, Baum RP, Schmidt M, et al. 177Lu-PSMA-617 therapy, dosimetry and follow-up in patients with metastatic castration-resistant prostate cancer. Nuklearmedizin. 2016;55(3):123-8.

19. Rahbar K, Schmidt M, Heinzel A, Eppard E, Bode A, Yordanova A, et al. Response and tolerability of a single dose of 177Lu-PSMA-617 in patients with metastatic castration-resistant prostate cancer: a multicenter retrospective analysis. J Nucl Med. 2016:57(9):1334-8.

20. Rahbar K, Bode A, Weckesser M, Avramovic N, Claesener M, Stegger L, et al. Radioligand therapy with 177Lu-PSMA-617 as a novel therapeutic option in patients with metastatic castration resistant prostate cancer. Clin Nucl Med. 2016;41(7):522-8

21. Rahbar K, Boegemann M, Yordanova A, Eveslage M, Schafers M, Essler M, et al. PSMA targeted radioligandtherapy in metastatic castration resistant prostate cancer after chemotherapy, abiraterone and/or enzalutamide. A retrospective analysis of overall survival. Eur J Nucl Med Mol Imaging. 2018;45(1):12-9.

22. Brauer A, Grubert LS, Roll W, Schrader AJ, Schafers M, Bogemann M, et al. (177) Lu-PSMA-617 radioligand therapy and outcome in patients with metastasized castration-resistant prostate cancer. Eur J Nucl Med Mol Imaging. 2017;44(10):1663-70.

23. Ahmadzadehfar H, Wegen S, Yordanova A, Fimmers R, Kurpig S, Eppard E, et al. Overall survival and response pattern of castration-resistant metastatic prostate cancer to multiple cycles of radioligand therapy using [(177) Lu] Lu-PSMA-617. Eur J Nucl Med Mol Imaging. 2017;44(9):1448-54.
24. Sjögreen Gleisner K, Spezi E, Solny P, Gabina PM, Cicone F, Stokke C, et al. Variations in the practice of molecular radiotherapy and implementation of dosimetry: results from a European survey. EJNMMI Physics. 2017;4(1):28.

25. Federal Office for Radiation Protection (Bundesamt für Strahlenschutz - BfS): Ordinance on the protection against damage and injuries caused by ionizing radiation (radiation protection ordinance) [Strahlenschutzverordnung]. 2001. https:/www.bfe.bund.de/SharedDocs/Downloads/BfE/DE/rsh/a1-englisch/A112-14.pdf?_blob=publicationFile\&v=1. Accessed 28 Oct 2017.

26. Fraenkel M, Kim M, Faggiano A, de Herder WW, Valk GD, Knowledge N. Incidence of gastroenteropancreatic neuroendocrine tumours: a systematic review of the literature. Endocr Relat Cancer. 2014;21(3):R153-63.

27. Yao JC, Hassan M, Phan A, Dagohoy C, Leary C, Mares JE, et al. One hundred years after "carcinoid": epidemiology of and prognostic factors for neuroendocrine tumors in 35,825 cases in the United States. J Clin Oncol. 2008:26(18):3063-72.

28. International Agency for Research on Cancer (IARC): European Cancer Observatory (ECO). 2012. http://eco.iarc.fr/Default.aspx. Accessed 25 Oct 2017

29. Siegel RL, Miller KD, Jemal A. Cancer statistics, 2015. CA Cancer J Clin. 2015; 65(1):5-29.

30. ICRP. Radiation dose to patients from radiopharmaceuticals: a compendium of current information related to frequently used substances. ICRP Publication 128. Ann ICRP. 2015;44(2S):7-321.

31. ICRP. The 2007 recommendations of the international commission on radiological protection. ICRP publication 103. Ann ICRP. 2007;37:1-332.

32. Council of the European Union. Council Directive 2013/59/Euratom of 5 December 2013. In: Off J Eur Union; 2014. https://ec.europa.eu/energy/sites/ ener/files/documents/CELEX-32013L0059-EN-TXT.pdf. Accessed 20 Oct 2017

33. Demir M, Abuqbeitah M, Uslu-Besli L, Yildirim O, Yeyin N, Cavdar I, et al. Evaluation of radiation safety in (177) Lu-PSMA therapy and development of outpatient treatment protocol. J Radiol Prot. 2016:36(2):269-78.

34. Federal Office for Radiation Protection (Bundesamt für Strahlenschutz - BfS): Directive on radiation protection in medicine [Richtlinie Strahlenschutz in der Medizin]. 2014. https://www.bfe.bund.de/SharedDocs/Downloads/BfE/ DE/rsh/3-bmub/3 17 0714.html. Accessed 25 Oct 2017.

35. German Commission on Radiological Protection [Strahlenschutzkommission - SSK]. Radiation protection principles for radioiodine therapy. Berlin; 1998. https://www.ssk.de/SharedDocs/Beratungsergebnisse_PDF/1996/1996_13e. pdf?_blob=publicationFile. Accessed 26 Oct 2017

36. Fitschen J, Knoop BO, Behrendt R, Knapp WH, Geworski L. External radiation exposure and effective half-life in Lu-177-Dota-Tate therapy. Z Med Phys. 2011;21(4):266-73.

37. Kossert K, Nahle OJ, Ott O, Dersch R. Activity determination and nuclear decay data of 177Lu. Appl Radiat Isot. 2012;70(9):2215-21.

38. Siegel JA, Thomas SR, Stubbs JB, Stabin MG, Hays MT, Koral KF, et al. MIRD pamphlet no. 16: techniques for quantitative radiopharmaceutical biodistribution data acquisition and analysis for use in human radiation dose estimates. J Nucl Med. 1999:40(2):37S-61S.

39. Buckley SE, Saran FH, Gaze MN, Chittenden S, Partridge M, Lancaster D, et al Dosimetry for fractionated (131) I-mIBG therapies in patients with primary resistant high-risk neuroblastoma: preliminary results. Cancer Biother Radiopharm. 2007:22(1):105-12.

40. Chittenden SJ, Pratt BE, Pomeroy K, Black P, Long C, Smith N, et al. Optimization of equipment and methodology for whole body activity retention measurements in children undergoing targeted radionuclide therapy. Cancer Biother Radiopharm. 2007:22(2):243-9.

41. Hindorf C, Glatting G, Chiesa C, Linden O, Flux G, Committee ED. EANM Dosimetry Committee guidelines for bone marrow and whole-body dosimetry. Eur J Nucl Med Mol Imaging. 2010;37(6):1238-50.

42. Kletting P, Kull T, Reske SN, Glatting G. Comparing time activity curves using the Akaike information criterion. Phys Med Biol. 2009:54(21):N501-7.

43. Kabasakal L, AbuQbeitah M, Aygun A, Yeyin N, Ocak M, Demirci E, et al. Pretherapeutic dosimetry of normal organs and tissues of (177) Lu-PSMA-617 prostate-specific membrane antigen (PSMA) inhibitor in patients with castrationresistant prostate cancer. Eur J Nucl Med Mol Imaging. 2015;42(13):1976-83.

44. Hohberg M, Eschner W, Schmidt M, Dietlein M, Kobe C, Fischer T, et al. Lacrimal glands may represent organs at risk for radionuclide therapy of prostate cancer with [(177) Lu] DKFZ-PSMA-617. Mol Imaging Biol. 2016;18(3):437-45.

45. Wehrmann C, Senftleben S, Zachert C, Muller D, Baum RP. Results of individual patient dosimetry in peptide receptor radionuclide therapy with 177Lu DOTA-TATE and 177Lu DOTA-NOC Cancer Biother Radiopharm. 2007;22(3):406-16. 
46. Esser JP, Krenning EP, Teunissen JJ, Kooij PP, van Gameren AL, Bakker WH, et al. Comparison of [(177) Lu-DOTA (0), Tyr (3)] octreotate and [(177) LuDOTA (0), Tyr (3)] octreotide: which peptide is preferable for PRRT? Eur J Nucl Med Mol Imaging. 2006;33(11):1346-51.

47. Calais PJ, Turner JH. Radiation safety of outpatient 177Lu-octreotate radiopeptide therapy of neuroendocrine tumors. Ann Nucl Med. 2014;28(6):531-9.

48. Liu B, de Blois E, Breeman WA, Konijnenberg MW, Wolterbeek HT, Bode P. Accurate assessment of whole-body retention for PRRT with (177) Lu using paired measurements with external detectors. Curr Radiopharm. 2015;8(2): 129-38.

49. Strosberg J, El-Haddad G, Wolin E, Hendifar A, Yao J, Chasen B, et al. Phase 3 trial of 177Lu-Dotatate for midgut neuroendocrine tumors. N Engl J Med. 2017;376(2):125-35.

50. Yordanova A, Mayer K, Brossart P, Gonzalez-Carmona MA, Strassburg CP, Essler M, et al. Safety of multiple repeated cycles of 177Lu-octreotate in patients with recurrent neuroendocrine tumour. Eur J Nucl Med Mol Imaging. 2017:44(7):1207-14.

51. Horsch D, Ezziddin S, Haug A, Gratz KF, Dunkelmann S, Miederer M, et al. Effectiveness and side-effects of peptide receptor radionuclide therapy for neuroendocrine neoplasms in Germany: a multi-institutional registry study with prospective follow-up. Eur J Cancer. 2016;58:41-51.

52. Buck AK, Stolzenburg A, Hanscheid H, Schirbel A, Luckerath K, Schottelius M, et al. Chemokine receptor-directed imaging and therapy. Methods. 2017; 130:63-71.

53. Dalm SU, Schrijver WA, Sieuwerts AM, Look MP, Ziel-van d, Made AC, de Weerd $\mathrm{V}$, et al. Prospects of targeting the gastrin releasing peptide receptor and somatostatin receptor 2 for nuclear imaging and therapy in metastatic breast cancer. PLoS One. 2017;12(1):e0170536.

54. Maina T, Nock BA, Kulkarni H, Singh A, Baum RP. Theranostic prospects of gastrin-releasing peptide receptor-radioantagonists in oncology. PET Clinics. 2017;12(3):297-309.

55. Kang CS, Chen Y, Lee H, Liu D, Sun X, Kweon J, et al. Synthesis and evaluation of a new bifunctional NETA chelate for molecular targeted radiotherapy using (90) Y or (177) Lu. Nucl Med Biol. 2015;42(3):242-9.

56. National Council on Radiation Protection and Measurements: NCRP report no. 123, screening models for releases of radionuclides to the atmosphere, surface water, and ground. 1996. http://ncrponline.org/publications/reports/ ncrp-reports-123/. Accessed 18 Jan 2018.

\section{Submit your manuscript to a SpringerOpen ${ }^{\circ}$ journal and benefit from:}

- Convenient online submission

- Rigorous peer review

- Open access: articles freely available online

- High visibility within the field

- Retaining the copyright to your article

Submit your next manuscript at $\gg$ springeropen.com 